
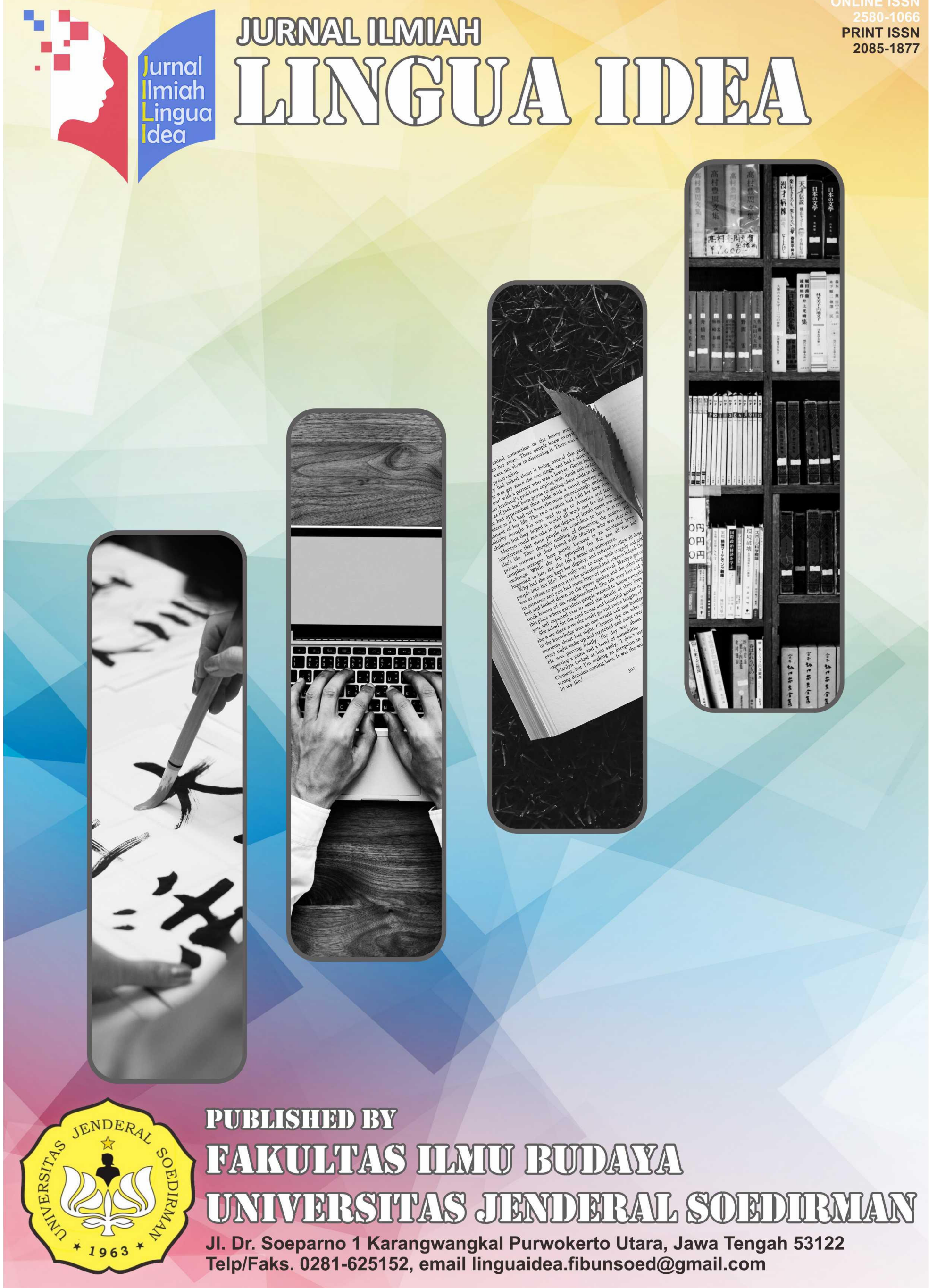
Editor in Chief

Dian Bayu Firmansyah, Fakultas Ilmu Budaya, Universitas Jenderal Soedirman, Indonesia; E-mail: dbayuf@unsoed.ac.id; (Scopus ID: 57200015393)

\section{Advisory Boards}

Aidatul Chusna, Fakultas Ilmu Budaya, Universitas Jenderal Soedirman, Indonesia

Ely Triasih Rahayu, Fakultas Ilmu Budaya, Universitas Jenderal Soedirman, Indonesia

\section{Editors}

Ambhita Dhyaningrum, Fakultas Ilmu Budaya, Universitas Jenderal Soedirman, Indonesia

Eko Kurniawan, Fakultas Ilmu Budaya, Universitas Jenderal Soedirman, Indonesia

Hanifa Pascarina, Fakultas Ilmu Budaya, Universitas Jenderal Soedirman, Indonesia

Bagus Reza Hariyadi, Fakultas Ilmu Budaya, Universitas Jenderal Soedirman, Indonesia

Vera Krisnawati, Fakultas Ilmu Budaya, Universitas Jenderal Soedirman, Indonesia

Lisda Nurjaleka, Fakultas Pendidikan Bahasa dan Seni, Universitas Negeri Semarang, Indonesia

\section{Reviewers}

Mister Gidion Maru, Universitas Manado, Indonesia

Ekawati Marhaenny Dukut, Unika Soegijapranata, Indonesia

Didik Rinan Sumekto, Universitas Widya Dharma, Indonesia

Nuriadi, Universitas Mataram, Indonesia

Agus Dwi Priyanto, Universitas Sebelas Maret, Indonesia

Henny Indarwati, Universitas Brawijaya, Indonesia

Lili Awaluddin, UIN Sunan Gunung Djati, Indonesia

\section{Editorial Office:}

Gedung B Fakultas Ilmu Budaya, Universitas Jenderal Soedirman

J1. Dr. Soeparno 1, Karangwangkal, Purwokerto Utara, Jawa Tengah 53122

Email : linguaidea@unsoed.ac.id

Website $\quad$ http://jos.unsoed.ac.id/index.php/jli/index 


\section{Focus and Scope}

Jurnal Ilmiah Lingua Idea which is published twice a year (every June and December), is a double blind peer-reviewed publication consists of research-based and review articles, fresh ideas about language, literature, cultural studies, and its teaching methodology, which have never been published before.

The journal covers all aspect relating to linguistics including:

1. Macro-linguistics;

2. Micro-linguistics;

3. Translation studies;

4. Post-colonial literature;

5. Modern literature;

6. Popular teen literature;

7. Cultural Studies;

8. Modern culture;

9. Popular culture;

10. Folk culture

11. Teaching methodology

12. Instructional media, etc. 


\section{JURNAL ILMIAH LINGUA IDEA}

ISSN 2086-1877 (Print); 2580-1066 (Online)

Volume 10, Issue 2, December 2019

Available Online at: http://jos.unsoed.ac.id/index.php/jli/index

Table of Contents

Wujud Kearifan Lokal dalam Bentuk dan Fungsi Folklor Lisan Banyumas

Lelono, B., Widjatini, R. (Universitas Jenderal Soedirman)

Nilai Kearifan dalam Babad Banyumas

Kuntarto., Widyaningsih, R., Chamadi, M. R. (Universitas Jenderal Soedirman)

Tindak Tutur Ilokusi Pengajar pada Proses Pembelajaran Bahasa Mandarin

Herliana, M., Suryadi, M. (Universitas Diponegoro)

89-105

Employing Website in Japanese Learning as an Instructional Media for Pedagogical

Purpose

Herniwati., Aneros, N., Judiasri, M. D. (Universitas Pendidikan Indonesia)

$106-114$

United Nations of Rendang: Meme dalam Perspektif Strukturalisme Lévi-Strauss

Hidayat, H. N. (Universitas Andalas)

Analisis Kontrastif Tindak Tutur Meminta Maaf dalam Bahasa Jepang dan Bahasa Sunda

Haristiani, N., Sopiyanti, A. (Universitas Pendidikan Indonesia)

Keterangan Waktu Non-Predikatif Bahasa Jepang

Roni, Didik Nurhadi (Universitas Negeri Surabaya) 